\title{
Role of Changes in Insulin and Glucagon in Glucose Homeostasis in Exercise
}

\author{
Robert R. Wolfe, Ethan R. Nadel, James H. F. Shaw, Lou A. Stephenson, and Marta H. Wolfe \\ The University of Texas Medical Branch and Shriners Burns Institute, Galveston, Texas 77550; and John B. Pierce Foundation \\ Laboratory, Yale University, School of Medicine, New Haven, Connecticut 06519
}

\begin{abstract}
This experiment was performed to determine if plasma glucose homeostasis is maintained in normal human volunteers during light exercise (40\% maximal oxygen consumption [نं $\mathbf{O}_{2}$ max]) when changes in insulin and glucagon are prevented. Hormonal control was achieved by the infusion of somatostatin, insulin, and glucagon. Glucose kinetics and oxidation rates were determined with stable isotopic tracers of glucose, and by indirect calorimetry. Two different rates of replacement of insulin and glucagon were used; in one group, insulin was clamped at 19.8 $\pm 2.6 \mu \mathrm{U} / \mathrm{ml}$ (high-insulin group), and in the other group insulin was clamped at $9.2 \pm 1.3 \mu \mathrm{U} / \mathrm{ml}$ (low-insulin group). Glucagon was maintained at $261 \pm 16.2$ and $124 \pm 6.4 \mathrm{pg} / \mathrm{ml}$, respectively, in the high-insulin and low-insulin groups.

Without hormonal control, plasma glucose homeostasis was maintained during exercise because the increase in glucose uptake was balanced by a corresponding increase in glucose production. When changes in insulin and glucagon were prevented, plasma glucose concentration fell, particularly in the high-insulin group. Glucose uptake increased to a greater extent than when hormones were not controlled, and glucose production did not increase sufficiently to compensate. The increase in glucose uptake in the hormonal control groups was associated with an increased rate of glucose oxidation. When euglycemia was maintained by glucose infusion in the hormonal control subjects, the modest increase in glucose production that otherwise occurred was prevented.

It is concluded that during light exercise there must be a reduction in insulin concentration and/or an increase in glucagon concentration if plasma glucose homeostasis is to be maintained. If such changes do not occur, hypoglycemia, and hence exhaustion, may occur.
\end{abstract}

\section{Introduction}

During the first 60 min of light exercise (30-40\% maximal oxygen consumption $\left.\left[\dot{\mathrm{VO}}_{2} \max \right]^{1}\right)$, plasma glucose homeostasis is maintained by an increase in hepatic glucose output that balances the increase in glucose uptake by working muscles (1). The role

Address correspondence to Dr. Wolfe, Shriners Burns Institute, The University of Texas Medical Branch, Galveston, TX 77550.

Received for publication 2 July 1985 and in revised form 12 November 1985.

1. Abbreviations used in this paper: E, basal plasma epinephrine; FFA, free fatty acids; IRMS, isotope ratio mass spectrometer; NE, norepinephrine; $\dot{\mathrm{VO}}_{2}$, oxygen consumption; $\dot{\mathrm{VO}}_{2} \max$, maximal oxygen consumption.

\section{J. Clin. Invest.}

(C) The American Society for Clinical Investigation, Inc.

0021-9738/86/03/0900/08 \$1.00

Volume 77, March 1986, 900-907 of insulin and glucagon as mediators of these changes in humans is generally considered to be minimal, since ordinarily, no change in their levels can be detected over the first $60 \mathrm{~min}$ of light exercise (1). The absence of a statistically significant change, however, does not rule out the possibility that a small but physiologically important change takes place. For example, altered hepatic clearance may minimize a change in peripheral insulin concentration even though changes in portal vein concentrations had occurred. Also, changes in sensitivity to insulin and glucagon could occur.

During strenuous exercise, or in prolonged light exercise, insulin levels fall significantly and glucagon concentration rises (2). Even in these circumstances, the precise role of these changes in maintaining glucose homeostasis is not clear. Studies in dogs $(3,4)$ have yielded contradictory results. Vranic et al. (3) studied pancreatectomized dogs and concluded that changes in insulin and glucagon concentration were not necessary for regulation of glucose concentration in exercise. In contrast, Issekutz and Vranic (4) used various combinations of somatostatin and glucagon infusion during exercise and found that the ratio of glucagon to insulin was directly correlated with glucose production. They concluded that glucagon plays a direct role in initiating and maintaining elevated glucose production in exercise. A more recent study in dogs has confirmed the importance of the glucagon response in stimulating glucose production in exercising dogs (5). It is not clear if conclusions from the dog can be directly extrapolated to humans, however, since the glucagon response to exercise in humans is not as marked as it is in the dog (5). In humans, if glucagon is free to change (6), a fall in insulin concentration is not necessary to maintain normal blood glucose concentration during exercise. This observation, however, made in studies of insulin-dependent diabetics, did not encompass the effects of simultaneous changes in insulin and glucagon in normal subjects.

The primary aim of this study was to determine in normal human volunteers if plasma glucose homeostasis could be maintained during light exercise when insulin and glucagon concentrations were held constant pharmacologically. A secondary aim of the study was to determine whether observed disruptions in glucose homeostasis under these conditions were due to changes in the rate of glucose production or the rate of glucose uptake. Another secondary aim was to investigate the relationship between changes in the rate of glucose uptake and the rate of oxidation. Finally, the role of plasma glucose concentration in regulating glucose production during exercise while insulin and glucagon were held constant has been investigated.

\section{Methods}

Experimental protocol. Five experimental protocols were used. In one control group $(n=4)$, somatostatin, insulin, glucagon, and stable isotopes of glucose were infused into resting subjects for $4 \mathrm{~h}$. The other four protocols consisted of three periods: basal, $90 \mathrm{~min}$; exercise, $60 \mathrm{~min}$; and recovery, $45 \mathrm{~min}$. One of the four exercise protocols was performed with 
no hormonal control $(n=8)$. Somatostatin, insulin, and glucagon were infused continuously throughout all three periods in the other three protocols to hold the hormone levels constant. In two of those protocols ( $n$ $=6$ in each), the insulin and glucagon infusion rates were chosen so that in one case the peripheral insulin and glucagon levels were significantly higher (high-insulin group) than in the other (low-insulin group). This was done so that in one case the normal portal insulin concentration was approximated (high-insulin group), while in the other case normal peripheral insulin concentrations were achieved (low-insulin group). In the final protocol, three subjects repeated the high-insulin group protocol, except that unlabeled glucose was infused during the exercise at a rate sufficient to maintain euglycemia.

11 normal male volunteers were studied while they were exercising. Six subjects completed both the high-insulin and low-insulin protocols during somatostatin infusion; three of those six also completed the exercise study without hormonal control. Those same three subjects repeated the high-insulin protocol, but received unlabeled glucose during exercise to maintain euglycemia. Five additional subjects were also studied without hormonal control. The subjects varied in their levels of fitness, but all were physically active, and some trained regularly. Their body weights and experimentally determined values for maximal oxygen consumption $\left(\dot{\mathrm{VO}}_{2} \mathrm{max}\right)$ are shown in Table $\mathrm{I}$. The four subjects who served as controls (no exercise) were different from the 11 subjects who participated in the exercise protocols. In all cases, informed consent was obtained before participation and after the experimental protocol had been explained in detail.

All experiments were performed with subjects $\sim 15-\mathrm{h}$ postabsorptive. At the start of the experiment a 17-gauge catheter for isotope infusion was inserted into a forearm vein and advanced $15 \mathrm{~cm}$ beyond the point of insertion. A 21-gauge butterfly catheter for collection of samples was inserted into a vein near the hand of the other arm. The hand was placed in a "warming box" before sampling in order to "arterialize" the venous blood (7). A blood sample was then drawn to determine the naturallyoccurring background enrichment of glucose before any isotope infusion, and five expired breath samples ( 5 liters) were collected to determine the background level of enrichment of expired $\mathrm{CO}_{2}$. Then, a primed-constant infusion of either $6,6-d_{2}$-glucose and $\left[\mathrm{U}-{ }^{13} \mathrm{C}\right]$ glucose, or of $\left[1{ }^{13} \mathrm{C}\right] \mathrm{glucose}$, was started and continued throughout the entire experimental protocol. A priming dose of $\mathrm{NaH}^{13} \mathrm{CO}_{3}$ was also administered at this time. Either approach allows an equivalent quantification of glucose kinetics and oxidation (8). Isotopes were obtained from Merck (Montreal, Canada). They were dissolved in sterile saline and passed through a 0.22 -micron filter (Millipore Corp., Bedford, MA) before infusion. The following infusion rates were used: $6,6-d_{2}$-glucose, $\sim 0.04 \mathrm{mg} / \mathrm{kg} \cdot \min$ (prime $=3.2$

Table I. Characteristics of Subjects

\begin{tabular}{lll}
\hline & Weight & vio $\max$ \\
\hline & $k g$ & $\mathrm{ml} / \mathrm{kg} \cdot \min$ \\
E.N. & 75 & 59.0 \\
S.X. & 75 & 45.0 \\
R.V. & 66 & 52.9 \\
R.H. & 84 & 36.9 \\
R.W. & 86 & 63.0 \\
H.A. & 73 & 42.2 \\
A.C. & 90 & 37.8 \\
J.N. & 64 & 65.6 \\
E.N. & 62 & 53.7 \\
R.H. & 63 & 61.8 \\
R.R. & 77 & 50.5 \\
\hline & & $\overline{\mathbf{x}}=51.6 \pm 3.05$ \\
\hline
\end{tabular}

$\mathrm{mg} / \mathrm{kg}$ ); $\left[\mathrm{U}-{ }^{13} \mathrm{C}\right]$ glucose, $\sim 0.006 \mathrm{mg} / \mathrm{kg} \cdot \min$ (prime $=0.5 \mathrm{mg} / \mathrm{kg}$ ); $\left[1-{ }^{13} \mathrm{C}\right.$ glucose, $\sim 0.055 \mathrm{mg} / \mathrm{kg} \cdot \mathrm{min}$ (prime $=4.3 \mathrm{mg} / \mathrm{kg}$ ); $\mathrm{NaH}^{13} \mathrm{CO}_{3}$ prime, $1.4 \mathrm{mg} / \mathrm{kg}$. All infusions were standardized using calibrated Harvard Syringe Pumps (Harvard Apparatus Co., S. Natick, MA). Exact infusion rates were determined for each subject by measuring the isotope concentration of the infusate using a Beckman glucose autoanalyzer (Beckman Instruments, Inc., Fullerton, CA) and multiplying by the calibrated infusion rate.

The three subjects who repeated the high-insulin protocol received an unlabeled glucose infusion at the rate of $2 \mathrm{mg} / \mathrm{kg} \cdot \mathrm{min}$ in order to maintain euglycemia throughout exercise. This infusion rate was selected on the basis of the experimentally determined change in the rate of glucose uptake that occurred the first time they performed the protocol (without exogenous glucose). In accord with the experiment performed by Cowan and Hetenyi (9), $\left[1{ }^{13} \mathrm{C}\right] \mathrm{glucose}$ was added to the exogenous glucose to minimize change in the plasma enrichment during exercise. The enrichment of the exogenous glucose matched the plasma enrichment in the basal period that was observed the first time the subjects performed the protocol. The same isotope infusion rate was used in the repeat experiment, and consequently the same plasma enrichment was obtained in the basal period. This was possible because of the small variation in glucose production from day to day in the same individual (10). Since the isotopic enrichment of the infused glucose was equal to the plasma glucose enrichment in the basal state, a change in plasma glucose enrichment during the exogenous glucose infusion had to reflect a change in endogenous glucose production.

Somatostatin for use in humans was obtained from Bachem (Torrance, $\mathrm{CA}$ ), and was dissolved in sterile saline for infusion. A stock solution of $1 \mathrm{mU} / \mathrm{ml}$ of insulin was made in a 25\% albumin solution, and further dilution for infusion was made in normal saline. Also, a stock solution of glucagon was made, from which an appropriate amount was added to saline for final infusion. The glucagon and somatostatin were added to the same solution, but the insulin solution was separate and infused by means of a different pump. In the early part of the somatostatin and hormone infusion, the plasma glucose concentration was checked frequently with the glucose autoanalyzer. If necessary, adjustments were made in the insulin infusion rate so that euglycemia was maintained. The zero time for the basal period was designated only after a stable baseline glucose concentration had been established. Once the basal period began, no further changes were made in either the insulin or glucagon infusion rates during the experimental period.

In groups receiving hormone infusion, somatostatin was infused at the rate of $0.1 \mu \mathrm{g} / \mathrm{kg} \cdot \mathrm{min}$. In the high-insulin group, insulin was infused at $\sim 0.2 \mathrm{mU} / \mathrm{kg} \cdot \min$, and glucagon was infused at $1.4 \mathrm{ng} / \mathrm{kg} \cdot \mathrm{min}$. In the low-insulin group, the insulin and glucagon infusion rates were $\sim 0.05$ $\mathrm{mU} / \mathrm{kg} \cdot \min$ and $0.8 \mathrm{ng} / \mathrm{kg} \cdot \mathrm{min}$, respectively.

During the basal period (time, 0-90 min), oxygen consumption $\left(\mathrm{V}_{2}\right)$ was determined twice for 5-min intervals by open circuit technique, with electronic analyzers that were calibrated with gases of known $\mathrm{O}_{2}$ and $\mathrm{CO}_{2}$ concentrations. Blood samples were drawn at $60,70,80$, and 90 min to determine basal kinetics. Expired breath was collected in 5-liter anesthesia bags every $5 \mathrm{~min}$ from $60 \mathrm{~min}$ to $90 \mathrm{~min}$, to determine $\mathrm{CO}_{2}$ enrichment. The $\mathrm{CO}_{2}$ was trapped in $0.1 \mathrm{~N} \mathrm{NaOH}$ for subsequent analyses (8). The exercise began after collection of the basal samples. Without interruption of infusion or change of body position, the subjects began to pedal against a fixed resistance on a cycle ergometer. The exercise intensity was set to approximate $40 \% \mathrm{VO}_{2}$ max, which averaged 400 $\mathrm{kpm} / \mathrm{min}$. The subjects wore a heart rate monitor, and if their heart rates exceeded 110 beats/min, the exercise intensity was reduced. The exercise was performed in a temperature-controlled room, the temperature of which was adjusted between 20 and $28^{\circ} \mathrm{C}$ for their comfort. Blood samples and expired breath samples were collected at 15, 30, 45, 52 , and $60 \mathrm{~min}$ of exercise. Indirect calorimetry determinations were made twice between 20-25 and 50-55 min of exercise. After the exercise was completed, the subjects remained in the same seated position for 45 min of recovery. Samples of breath and blood were taken at 15, 30, and 45 min during the recovery period.

The $\mathrm{VO}_{2}$ max was determined on a separate occasion for each subject. 
Each subject exercised on a cycle ergometer for $5 \mathrm{~min}$ at $\sim 50 \%$ of the estimated $\mathrm{VO}_{2}$ max. After a short rest period, exercise was resumed at that intensity. Every $2 \mathrm{~min}$ thereafter the exercise intensity was increased by $180 \mathrm{kpm} / \mathrm{min}$. Criteria for achievement of $\mathrm{VO}_{2} \max$ were failure to keep up with cadence of pedalling, a respiratory exchange coefficient $(R)$ of greater than 1.05 , and a leveling off of $\mathrm{VO}_{2}$ with increasing intensity.

Analysis of samples. Blood samples were kept on ice, quickly centrifuged, and the plasma separated. Plasma for glucagon analysis was placed in prechilled tubes with $\mathrm{NA}_{2}$ EDTA and aprotinin. Plasma for catecholamine analysis was transferred to tubes containing reduced glutathione, frozen and stored at $-70^{\circ} \mathrm{C}$ until analysis. Insulin (11) and glucagon (12) were analyzed via radioimmunoassay. Catecholamines were analyzed using high pressure liquid chromatography on a high pressure liquid chromatograph (5000; Varian Associates, Palo Alto, CA) using a Biophase ODS $\mu \mathrm{M}$ column and Lc4A detector (Bioanalytical Systems, W. Lafayette, IN) (13). Plasma free fatty acid (FFA) concentrations were measured by gas chromatography using an internal standard on a Varian 2100/CDS 111 system (Varian Associates). Plasma glucose concentration was measured using a glucose autoanalyzer (Beckman Instruments, Inc.). The pentacetate derivative of plasma glucose was used for analysis of isotopic enrichment of $6,6-d_{2}$-glucose and $\left[1-{ }^{13} \mathrm{C}\right]$ glucose by means of a gas chromatograph mass spectrometer (5985B; HewlettPackard Co., Palo Alto, CA). Enrichment of $6,6-d_{2}$-glucose was determined using electron impact ionization and the selective monitoring of ions at $\mathrm{m} / \mathrm{e} 200.1$ and 202.2 . Enrichment of $\left[1{ }^{13} \mathrm{C}\right]$ glucose was determined by monitoring ions at $\mathrm{m} / \mathrm{e} 331$ and 332 using chemical ionization with methane reactant gas. These ions contain carbons 1-6; enrichment at carbons $2-6$ was then determined by monitoring ions at $\mathrm{m} / \mathrm{e} 242$ and 243 , in the electron impact mode, which do not contain the 1-carbon. Enrichment at the 1-carbon was then calculated by subtraction. When $\left[\mathrm{U}-{ }^{13} \mathrm{C}\right]$ glucose was used, the glucose was isolated by ion-exchange chromatography and then combusted at $1,000^{\circ} \mathrm{C}$ in a vacuum. The resulting $\mathrm{CO}_{2}$ was trapped and analyzed on an isotope ratio mass spectrometer (IRMS) as described previously (10). Similarly, expired $\mathrm{CO}_{2}$ enrichment was determined by IRMS (10).

Calculations. In the basal state, an isotopic equilibrium was achieved in glucose enrichment and in expired $\mathrm{CO}_{2}$ enrichment in all experiments. In the case of 6,6- $d_{2}$-glucose, the rate of glucose production $\mathrm{Ra}(\mathrm{gl})$ was thus calculated by: $R \mathbf{a}(\mathrm{gl})=\left(\mathrm{F}^{\prime} / \mathrm{E}\right)-\mathrm{F}$, where $\mathrm{F}^{\prime}=$ isotope infusion rate ( $\mathrm{mg} \mathrm{d}_{2}$-glucose $/ \mathrm{kg} \cdot \mathrm{min}$ ), $F=$ total isotope infusion rate $(\mathrm{mg} / \mathrm{kg} \cdot \mathrm{min})$, and $\mathrm{E}=$ plasma glucose isotopic enrichment (mole percent excess, MPE).

When $\left[1-{ }^{13} \mathrm{C}\right]$ glucose was used, the recycling of labeled carbons was accounted for. Thus: $\mathrm{Ra}$ (gl) $=\left(\mathrm{F}^{\prime} / \mathrm{E}_{\text {glucose (carbon 1) }}-\mathrm{E}_{\text {glucosec carbon (2-6)/3) }}\right.$ $-F$. The enrichment of carbons $2-6$ was divided by 3 because the recycled glucose could appear in the 2, 5, or 6 position. These two approaches yield equal rates of $\mathbf{R a}(\mathrm{gl})(8)$.

During exercise, the isotopic steady state was disrupted and therefore the non-steady-state equations of Steele (14) were used to calculate glucose kinetics. These calculations require the assumption of a constant "apparent" volume of distribution space of glucose $(V)$. The value of $V$ $=100 \mathrm{ml} / \mathrm{kg}$ was chosen for these experiments. In addition, data were calculated using values ranging from 40 to $210 \mathrm{ml} / \mathrm{kg}$. Our conclusions are not affected by the assumed value for $V$, since the total difference in calculated values was never more than $10 \%$ for any set of data.

In the basal state, the expired $\mathrm{CO}_{2}$ enrichment reflected isotopic equilibrium, but non-steady-state kinetics of ${ }^{13} \mathrm{CO}_{2}$ were observed in exercise (Fig. 1). Nonetheless, for comparative purposes, the rate of ${ }^{13} \mathrm{CO}_{2}$ expiration is presented, since the nature of the disruption of steady state kinetics was similar in the three groups. In calculating total ${ }^{13} \mathrm{CO}_{2}$ excretion, the alteration during exercise in $\mathrm{H}^{13} \mathrm{CO}_{2}$ retention was accounted for by using recovery data from a previous experiment in which $\mathrm{NaH}^{13} \mathrm{CO}_{3}$ was infused throughout rest and exercise (15).

Statistics. The primary statistical approach was the comparison of the exercise and recovery data with the basal data of the same group by using Dunnett's $t$ test. If comparisons between groups at a particular

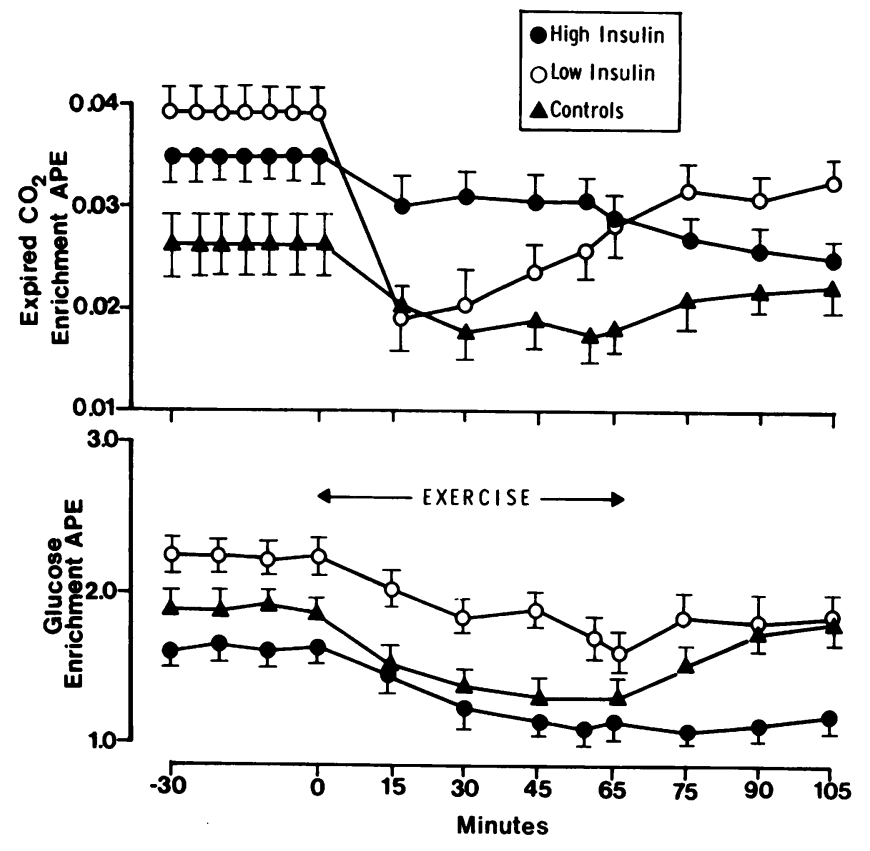

Figure 1. Isotope enrichments of expired $\mathrm{CO}_{2}$ and plasma glucose at rest, during exercise, and in recovery, expressed in atom percent $(A P E)$. Values are mean \pm SEM. Three groups were: controls $(\Lambda)$; somatostatin plus hormone infusion (high-insulin groups) (๑); and somatostatin plus hormone infusion (low-insulin group) (0). The basal period started at $-90 \mathrm{~min}$.

time were made, analysis of variance and Newman-Keuls post-hoc test were used.

\section{Results}

When hormones were not infused, insulin concentration decreased slightly during exercise, with lower values at 45 and 60 min of exercise than in the basal period $(P<0.05)$ (Table II). Glucagon concentration appeared to increase slightly in exercise, but the change was not statistically significant. With hormonal control, no significant changes in insulin or glucagon occurred throughout the entire experimental protocol (Tables III and IV). In the high-insulin group, the insulin level was constant at $\sim 20$ $\mu \mathrm{U} / \mathrm{ml}$, and glucagon remained $\sim 260 \mathrm{pg} / \mathrm{ml}$ (Table III); the insulin and glucagon values in the low-insulin group were $\sim 9$ $\mu \mathrm{U} / \mathrm{ml}$ and $130 \mathrm{pg} / \mathrm{ml}$, respectively (Table IV).

In some subjects, the plasma glucose level fell as hormonal control was begun, and in some, it rose. Quickly modifying the rate of insulin infusion, however, usually enabled a constant blood glucose level to be maintained. Once the basal period started, no further changes in the infusions were made. In the control group, who did not exercise, stable levels of glucose concentration and enrichment were maintained during $4 \mathrm{~h}$ of infusion (Fig. 2). In these control subjects, the average insulin concentration was $11.1 \pm 2.0 \mu \mathrm{U} / \mathrm{ml}$, and the glucagon concentration was $141 \pm 16.8 \mathrm{pg} / \mathrm{ml}$. Because of the consistency of the values in the control subjects over $4 \mathrm{~h}$ of isotope infusion, the values obtained during exercise and recovery in the experimental groups were compared statistically with the basal values for the same group. 
Table II. Hormone Concentrations in Control Subjects at Rest and in Exercise

\begin{tabular}{|c|c|c|c|c|c|c|c|c|c|}
\hline & Basal & E15 & E30 & E45 & E52 & E60 & R15 & R30 & R45 \\
\hline \multicolumn{10}{|l|}{ Insulin } \\
\hline$(\mu U / m l)$ & $13.2 \pm 1.4$ & $10.3 \pm 1.2$ & $9.4 \pm 1.2$ & $8.6 \pm 0.09^{*}$ & $8.7 \pm 1.2$ & $8.4 \pm 1.1^{*}$ & $10.2 \pm 2.1$ & $11.4 \pm 2.2$ & $11.4 \pm 1.8$ \\
\hline \multicolumn{10}{|l|}{ Glucagon } \\
\hline$(p g / m l)$ & $142 \pm 36$ & $207 \pm 43$ & $194 \pm 34$ & $201 \pm 44$ & $194 \pm 36$ & $199 \pm 37$ & $188 \pm 66$ & $164 \pm 29$ & $153 \pm 32$ \\
\hline \multicolumn{10}{|c|}{ Epinephrine } \\
\hline$(p g / m l)$ & $36 \pm 10.1$ & $77 \pm 27.8$ & $87 \pm 27.3^{*}$ & $92 \pm 26.3^{*}$ & $105 \pm 46.7^{*}$ & $111 \pm 31.2^{*}$ & $54 \pm 18.0$ & $50 \pm 12.4$ & $47 \pm 12.7$ \\
\hline \multicolumn{10}{|c|}{ Norepinephrine } \\
\hline$(p g / m l)$ & $204 \pm 14$ & $502 \pm 19^{*}$ & $570 \pm 27^{*}$ & $621 \pm 44^{*}$ & $562 \pm 24^{*}$ & $606 \pm 46^{*}$ & $300 \pm 27^{*}$ & $243 \pm 15$ & $239 \pm 42$ \\
\hline
\end{tabular}

Numbers preceded with $\mathrm{E}$ refer to minutes of exercise; numbers preceded with $\mathrm{R}$ refer to minutes of recovery. * Significantly different from basal value, $P<0.05 ; n=8$.

Exercise caused an approximate sevenfold increase in $\mathrm{VO}_{2}$. The $\dot{\mathrm{VO}}_{2}$ was $37.0 \%$ of the $\dot{\mathrm{VO}}_{2}$ max in the control group, and $38.9 \%$ and $41.9 \%$ of $\mathrm{VO}_{2}$ max in the high-insulin and low-insulin groups, respectively (Table V). Although the percentage of $\dot{\mathrm{V}}_{2}$ max was higher in the somatostatin groups than the controls, the difference was not statistically significant.

The basal plasma glucose concentrations did not vary significantly among the groups (Fig. 3). When exercise began, however, the responses were divergent. In the controls, euglycemia was maintained throughout exercise and recovery. In the somatostatin-treatment groups, the plasma glucose level dropped at the start of exercise (Fig. 3). In the high-insulin group, glucose fell precipitously and failed to rebound in recovery. Two subjects in this group could not complete the $60 \mathrm{~min}$ of exercise, and two additional subjects became symptomatic of hypoglycemia during recovery. All were revived by intravenous infusion of dextrose (D-50) at the completion of the study. In this group, all subjects complained of total exhaustion, despite the fact that the mean heart rate was only $111 \pm 4$ beats/min during exercise. In the low-insulin group, the glucose concentration also fell during exercise, but because of the variability in response only the value at $60 \mathrm{~min}$ was significantly lower than the basal value.

The glucose concentration dropped during exercise in the two somatostatin treatment groups because the rate of glucose uptake increased to a markedly greater extent than did the rate of glucose production (Fig. 4). All groups had comparable increases in glucose production. The higher rates of glucose uptake during exercise, relative to production, of the hormonal control groups were associated with higher rates of excretion of ${ }^{13} \mathrm{CO}_{2}$ from the infused ${ }^{13} \mathrm{C}$-glucose (Fig. 5), and with significantly higher values for the respiratory exchange coefficient (R) (Table V). Both of these observations indicate higher rates of glucose oxidation in the hormonal control groups.

The different insulin infusion rates had a pronounced effect on basal FFA concentrations. The high-insulin group had significantly depressed FFA levels in the basal state and throughout exercise (Table VI), as compared with the other groups. The FFA levels in the low-insulin group were higher than those of the controls, but the difference was significant only in the recovery period. In the low-insulin group, FFA levels were significantly higher during recovery than during exercise. Although there was a similar pattern in the other two groups, the response was not statistically significant.

Basal plasma epinephrine (E) and norepinephrine (NE) levels were comparable in all three groups. During exercise, $\mathrm{E}$ and NE rose moderately in the controls and the low-insulin group (Tables II and III). The total epinephrine response was greater in the low-insulin group. The high-insulin group had a much more pronounced increase in both $\mathrm{NE}$ and $\mathrm{E}$ (Table III). The E level rose from a basal value of $129 \pm 24 \mathrm{pg} / \mathrm{ml}$ to a peak concentration of $1,405 \pm 114 \mathrm{pg} / \mathrm{ml}$ at $52 \mathrm{~min}$ of exercise in the high-insulin group. The elevations in $\mathrm{E}$ and $\mathrm{NE}$ in the high-insulin group persisted through the recovery period (Table III).

When the high-insulin protocol was repeated in three subjects, but with exogenous glucose being infused in the repeat experiment, euglycemia was maintained throughout exercise. In each case, the isotopic enrichment of the exogenous glucose was within 5\% of the basal plasma glucose enrichment (Table VII).

Table III. Hormone Concentrations at Rest and in Exercise during Infusion of Somatostatin, Insulin, and Glucagon

\begin{tabular}{|c|c|c|c|c|c|c|c|c|c|}
\hline & Basal & E15 & E30 & E45 & E52 & E60 & R15 & R30 & R45 \\
\hline \multicolumn{10}{|l|}{ Insulin } \\
\hline$(\mu U / m l)$ & $19.8 \pm 2.6$ & $21.8 \pm 3.5$ & $19.8 \pm 2.6$ & $20.2 \pm 3.2$ & $20.1 \pm 3.1$ & $21.2 \pm 4.1$ & $20.4 \pm 3.0$ & $20.2 \pm 3.4$ & $20.4 \pm 3.5$ \\
\hline \multicolumn{10}{|l|}{ Glucagon } \\
\hline$(p g / m l)$ & $262 \pm 66$ & $246 \pm 66$ & $282 \pm 75$ & $271 \pm 76$ & $287 \pm 73$ & $240 \pm 64$ & $252 \pm 36$ & $263 \pm 41$ & $249 \pm 29$ \\
\hline \multicolumn{10}{|l|}{ Epinephrine } \\
\hline$(p g / m l)$ & $72 \pm 10$ & $129 \pm 24^{*}$ & $498 \pm 96^{*} \ddagger$ & $1,001 \pm 172 * \ddagger$ & $1,405 \pm 114^{*} \ddagger$ & $1,074 \pm 69^{*} \ddagger$ & $854 \pm 223^{*} \ddagger$ & $946 \pm 84^{*} \ddagger$ & $765 \pm 143^{*} \ddagger$ \\
\hline \multicolumn{10}{|l|}{ Norepinephrine } \\
\hline$(p g / m l)$ & $178 \pm 22$ & $954 \pm 171^{*} \ddagger$ & $1,130 \pm 242^{*} \ddagger$ & $1,039 \pm 125^{*} \ddagger$ & $1,035 \pm 186^{*} \ddagger$ & $1,016 \pm 100^{*} \ddagger$ & $478 \pm 86^{*}$ & $630 \pm 72 * \ddagger$ & $513 \pm 132 * \ddagger$ \\
\hline
\end{tabular}

The following infusion rates were used: somatostatin, $0.1 \mu \mathrm{g} / \mathrm{kg} \cdot \mathrm{min}$; insulin (approx.), $0.2 \mathrm{mU} / \mathrm{kg} \cdot \min ;$ glucagon, $1.4 \mathrm{ng} / \mathrm{kg} \cdot \min ($ high-insulin group) $(n=6)$ ) $*$ Significantly different from basal value $(P<0.05)$. $\ddagger$ Significantly different from control at same time $(P<0.05)$. 
Table IV. Hormone Concentrations at Rest and in Exercise during Infusion of Somatostatin, Insulin, and Glucagon

\begin{tabular}{|c|c|c|c|c|c|c|c|c|c|}
\hline & Basal & E15 & E30 & E45 & E52 & E60 & R15 & $\mathbf{R} 30$ & R45 \\
\hline \multicolumn{10}{|l|}{ Insulin } \\
\hline$(\mu U / m l)$ & $9.2 \pm 1.3$ & $10.1 \pm 1.2$ & $9.4 \pm 1.0$ & $9.5 \pm 0.8$ & $9.2 \pm 0.9$ & $9.0 \pm 0.9$ & $9.3 \pm 1.0$ & $9.4 \pm 1.0$ & $9.0 \pm 1.0$ \\
\hline \multicolumn{10}{|l|}{ Glucagon } \\
\hline$(p g / m l)$ & $115 \pm 61$ & $130 \pm 62$ & $123 \pm 57$ & $122 \pm 61$ & $128 \pm 59$ & $131 \pm 62$ & $119 \pm 61$ & $134 \pm 58$ & $120 \pm 69$ \\
\hline \multicolumn{10}{|c|}{ Epinephrine } \\
\hline$(p g / m l)$ & $27 \pm 12$ & $107 \pm 32$ & $149 \pm 43^{*}$ & $116 \pm 34^{*}$ & $127 \pm 38^{*}$ & $138 \pm 34^{*}$ & $52 \pm 16$ & $55 \pm 20$ & $60 \pm 20$ \\
\hline \multicolumn{10}{|c|}{ Norepinephrine } \\
\hline$(p g / m l)$ & $288 \pm 58$ & $772 \pm 171^{*}$ & $597 \pm 242^{*}$ & $611 \pm 278^{*}$ & $705 \pm 186^{*}$ & $681 \pm 198^{*}$ & $238 \pm 86$ & $249 \pm 61$ & $245 \pm 49$ \\
\hline
\end{tabular}

The following infusion rates were used: somatostatin, $0.1 \mu \mathrm{g} / \mathrm{kg} \cdot \mathrm{min}$; insulin (approx.), $0.05 \mathrm{mU} / \mathrm{kg} \cdot \mathrm{min} ; \mathrm{glucagon}, 0.8 \mathrm{ng} / \mathrm{kg} \cdot \mathrm{min}(\mathrm{low}-\mathrm{insulin}$ group) $(n=6)$. * Significantly different from basal value $(P<0.05)$.

In each experiment there was a slight increase in the enrichment of the plasma glucose during exercise, indicating a reduction (below basal) of endogenous production. However, these changes were not statistically significant. All three subjects completed the exercise easily, whereas when glucose was not infused, one subject had not completed the exercise and the other two had had great difficulty. In the recovery period, plasma glucose enrichment became significantly higher than the basal value, indicating a suppression of endogenous production.

\section{Discussion}

The results of this study indicate that in human subjects glucose homeostasis is disrupted in light exercise when changes in insulin and glucagon concentrations are prevented pharmacologically. Plasma glucose concentration fell during exercise with hormonal control because the rate of glucose uptake was accelerated above normal, and the increase in glucose production that occurred simultaneously was not sufficient to fully compensate. The increase in glucose uptake during exercise with hormonal control was associated with a higher rate of glucose oxidation. The increase in glucose production that occurred with hormonal control was apparently a compensatory response to hypoglycemia, since
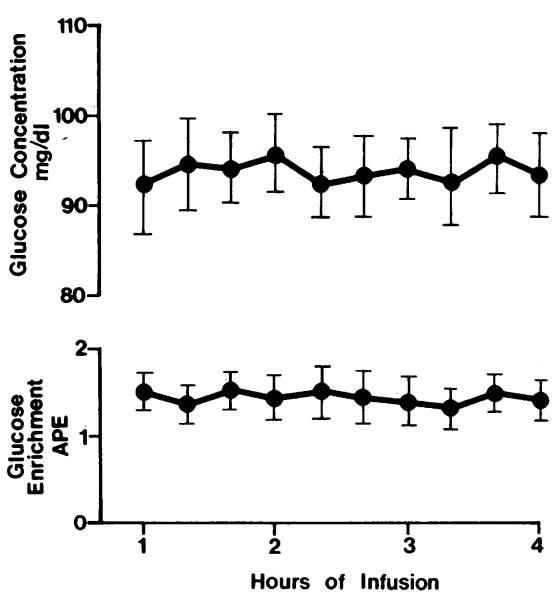

Figure 2. Glucose concentration and glucose enrichment in five volunteers at rest for $4 \mathrm{~h}$ after the start of constant infusions of somatostatin, insulin, and glucagon. Values are mean \pm SEM. when euglycemia was maintained by glucose infusion during the same exercise conditions, endogenous glucose production did not increase.

The reduction in glucose concentration that occurred during exercise in the hormonal control groups was not attributable to a direct effect of somatostatin, since hypoglycemia does not develop during exercise in humans when somatostatin is infused without hormonal replacement (16). Also, when no exercise load was imposed on the subjects, normal values for glucose concentration and production were maintained for $4 \mathrm{~h}$. Furthermore, Cherrington and associates (17) have demonstrated that there are minimal direct effects of somatostatin on the metabolism of glucose.

This is not to say, however, that the peripheral infusion of somatostatin, insulin, and glucagon is optimal for the control of insulin and glucagon levels in humans, since this pharmacological approach disrupts the normal gradient from the portal vein to peripheral blood (18). In an attempt to account for this potential problem, we used two different hormone infusion rates,

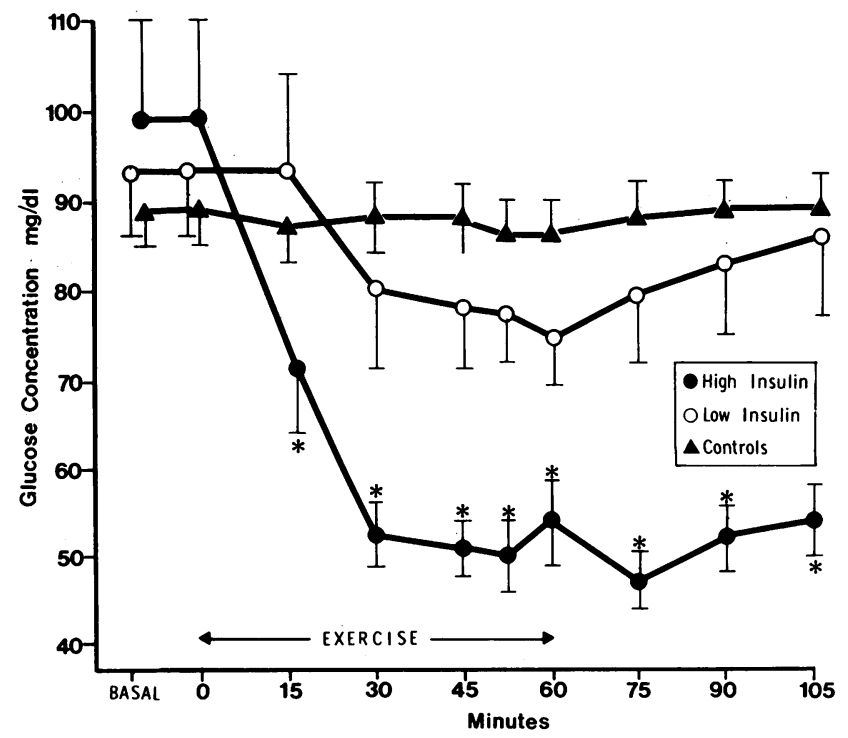

Figure 3. Plasma glucose concentration in rest, exercise, and recovery. Symbols are as in Fig. 1. Values are mean \pm SEM. *Significantly different from basal value of the same group $(P>0.05)$. 
Table V. Indirect Calorimetry Data at Rest and during Exercise

\begin{tabular}{|c|c|c|c|c|}
\hline & Basal & E20 & E50 & Recovery \\
\hline \multicolumn{5}{|l|}{ Control } \\
\hline$\dot{\mathrm{V}} \mathrm{O}_{2}(\mu \mathrm{mol} / \mathrm{kg} \cdot \mathrm{min})$ & $121 \pm 4.1$ & $673 \pm 36.4$ & $661 \pm 16.3$ & $149 \pm 12.4$ \\
\hline$\% \dot{\mathrm{VO}}_{2} \max$ & - & $37.2 \pm 5.1$ & $36.8 \pm 4.8$ & - \\
\hline$\dot{\mathrm{V}} \mathrm{CO}_{2}(\mu \mathrm{mol} / \mathrm{kg} \cdot \mathrm{min})$ & $91 \pm 2.4$ & $558 \pm 43.2$ & $528 \pm 15.6$ & $116.2 \pm 90.3$ \\
\hline $\mathbf{R}$ & $0.75 \pm 0.009$ & $0.83 \pm 0.017^{*}$ & $0.80 \pm 0.012^{*}$ & $0.78 \pm 0.010$ \\
\hline \multicolumn{5}{|l|}{ Somatostatin (high-insulin) } \\
\hline$\dot{\mathrm{V}} \mathrm{O}_{2}(\mu \mathrm{mol} / \mathrm{kg} \cdot \mathrm{min})$ & $110.5 \pm 8.8$ & $795 \pm 64.0$ & $802 \pm 29.8$ & $976 \pm 15.3$ \\
\hline$\% \dot{\mathrm{VO}}_{2} \max$ & - & $38.7 \pm 4.0$ & $38.9 \pm 4.0$ & - \\
\hline$\dot{\mathrm{V}} \mathrm{CO}_{2}(\mu \mathrm{mol} / \mathrm{kg} \cdot \mathrm{min})$ & $81.4 \pm 7.4$ & $723 \pm 48.6$ & $737 \pm 12.8$ & $771 \pm 12.4$ \\
\hline $\mathbf{R}$ & $0.74 \pm 0.012$ & $0.91 \pm 0.015^{*} \ddagger$ & $0.92 \pm 0.014^{*} \ddagger$ & $0.79 \pm 0.048$ \\
\hline \multicolumn{5}{|l|}{ Somatostatin (low-insulin) } \\
\hline$\dot{\mathrm{VO}}_{2}(\mu \mathrm{mol} / \mathrm{kg} \cdot \mathrm{min})$ & $108 \pm 18.0$ & $864 \pm 61.9$ & $848 \pm 42.9$ & $126 \pm 23.4$ \\
\hline$\% \dot{\mathrm{V}}_{2} \max$ & - & $42.1 \pm 4.4$ & $41.7 \pm 6.4$ & - \\
\hline$\dot{\mathrm{V} C O}{ }_{2}(\mu \mathrm{mol} / \mathrm{kg} \cdot \mathrm{min})$ & $80.1 \pm 12.4$ & $765 \pm 49.4$ & $771.7 \pm 19.8$ & $102 \pm 12.4$ \\
\hline $\mathbf{R}$ & $0.74 \pm 0.004$ & $0.88 \pm 0.007^{*} \ddagger$ & $0.91 \pm 0.006^{*} \ddagger$ & $0.81 \pm 0.015$ \\
\hline
\end{tabular}

* Significantly different from basal value in same group, $P<0.05$. $¥$ Significantly different from control value at same time, $P<0.05$. Percent of $\dot{\mathrm{V}}_{2}$ max was calculated for each individual using experimentally determined $\dot{\mathrm{VO}}_{2}$ max.

one of which was aimed at maintaining normal portal levels of insulin and glucagon, and the other was aimed at maintaining normal peripheral hormone levels. In each case, we placed primary emphasis on the comparison of the exercise and recovery data with the basal data for the same group.

The increase in glucose uptake that occurred during exercise with hormonal control could have resulted from either an increased sensitivity to the action of insulin to stimulate glucose transport, or from increased intracellular metabolism of glucose resulting from a mechanism other than enhanced insulin sen-
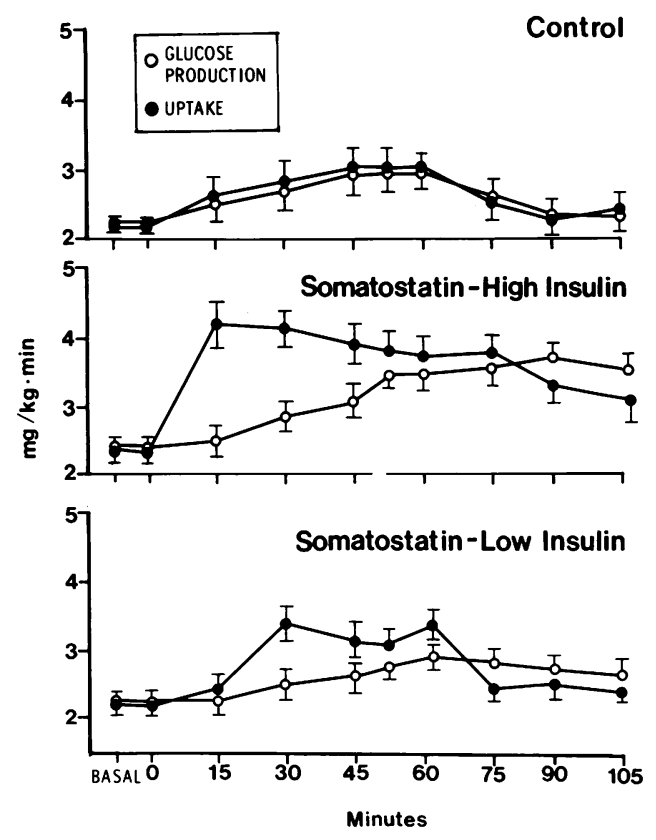

Figure 4. Glucose production and uptake in exercise. Symbols are as in Fig. 1. sitivity. Several lines of evidence favor an increased peripheral sensitivity to the action of insulin in exercise. Increased insulin sensitivity has been previously reported in monocytes taken from human subjects after exercise (19). In the isolated perfused rat hindquarter, exercise stimulated glucose uptake only in the presence of insulin (20), and in the same preparation an increased sensitivity to insulin in recovery from exercise has been demonstrated (21). In contrast, it does not seem likely that decreased availability of other energy substrates was responsible for stimulating glucose oxidation, and thus uptake. Glucose oxidation increased to a similar extent in both the high-insulin and lowinsulin groups, although there was a marked difference in the FFA levels in the two groups. Whereas it is possible that there is another factor in exercise that drives the rate of glucose uptake,

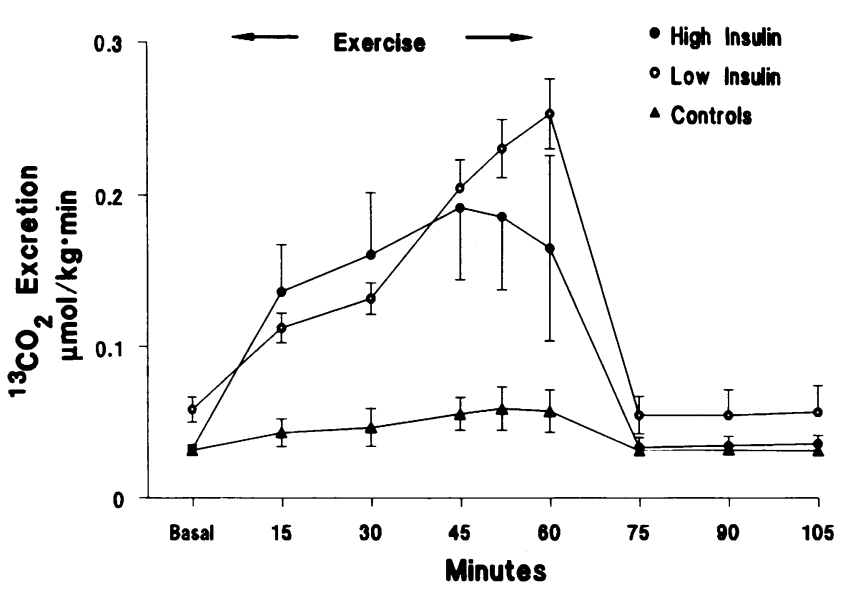

Figure 5. Total ${ }^{13} \mathrm{CO}_{2}$ excretion in exercise and recovery. ${ }^{13} \mathrm{CO}_{2}$ excretion was corrected for changes in bicarbonate kinetics, as determined in a separate experiment in which $\mathrm{NAH}^{13} \mathrm{CO}_{3}$ was infused continuously, according to the same exercise protocol used in this experiment (17). Symbols are as in Fig. 1. 
Table VI. Plasma Free Fatty Acid Concentration in Exercise

\begin{tabular}{|c|c|c|c|c|c|c|c|c|c|}
\hline & Basal & E15 & E30 & E45 & E52 & E60 & R15 & R30 & R45 \\
\hline $\begin{array}{l}\text { Control } \\
\text { Somatostatin }\end{array}$ & $0.42 \pm 0.09$ & $0.57 \pm 0.14$ & $0.56 \pm 0.14$ & $0.58 \pm 0.12$ & $0.58 \pm 0.12$ & $0.49 \pm 0.14$ & $0.74 \pm 0.21$ & $0.68 \pm 0.11$ & $0.60 \pm 0.13$ \\
\hline $\begin{array}{l}\text { (high insulin) } \\
\text { Somatostatin }\end{array}$ & $0.18 \pm 0.03$ & $0.13 \pm 0.02 \ddagger$ & $0.14 \pm 0.02 \ddagger$ & $0.16 \pm 0.03 \ddagger$ & $0.18 \pm 0.04 \ddagger$ & $0.18 \pm 0.03 \ddagger$ & $0.23 \pm 0.04 \ddagger$ & $0.32 \pm 0.07 \ddagger$ & $0.32 \pm 0.06 \ddagger$ \\
\hline (low insulin) & $0.69 \pm 0.10$ & $0.52 \pm 0.09$ & $0.64 \pm 0.13$ & $0.73 \pm 0.18$ & $0.67 \pm 0.16$ & $0.70 \pm 0.16$ & $1.02 \pm 0.23^{*} \ddagger$ & $1.02 \pm 0.21^{*} \ddagger$ & $0.94 \pm 0.22 *$ \\
\hline
\end{tabular}

Units are $\mu \mathrm{mol} / \mathrm{ml}$. * Significantly different from basal value in same group, $P<0.05$. $¥$ Significantly different from control value at same time, $P<0.05$.

independent of insulin action, no such factor has been identified (20).

The inability of the high-insulin group to return to normoglycemia during the recovery period was striking. The elevated demand for energy during exercise was largely eliminated, yet all subjects became symptomatically hypoglycemic and recovered almost immediately when dextrose (D-50) was infused intravenously upon termination of the experiment. This observation adds further support to the concept of increased peripheral sensitivity to insulin, since the glucose oxidation rate in recovery decreased in accord with the fall in total energy expenditure, yet nonetheless glucose uptake remained above the basal level. In the setting of constant levels of insulin and glucagon, the increased insulin sensitivity and stimulus for the resynthesis of muscle glycogen during recovery (21) apparently superceded the mechanisms available to cause a restoration of normoglycemia. There may be a latency for the recovery of baseline insulin sensitivity following exercise.
Although the rate of glucose production increased during exercise in the hormonal control groups, it did not increase sufficiently to offset the increase in glucose uptake. This was probably due to both the inability of glucagon to respond, as well as the failure of insulin to decrease. The increase in glucose production in exercise with hormonal control was a response to hypoglycemia, since when euglycemia was maintained by glucose infusion, there was a modest drop in endogenous glucose production (rather than an increase). The experimental protocol in which glucose was infused during hormonal control was patterned after the recent experiment in exercising dogs reported by Wasserman et al. (5), with the exception that they did not replace the hormones during the somatostatin infusion. They found that when euglycemia was maintained in exercise by the infusion of glucose, the increase in glucose production that normally occurred was attenuated, but nonetheless glucose production still rose significantly. It is possible that the sensitivity of the liver of those dogs to glucagon was increased by the low

Table VII. Plasma Glucose Concentration and Enrichment during Exercise with Glucose Infusion

\begin{tabular}{|c|c|c|c|c|c|c|c|c|}
\hline \multirow[b]{2}{*}{ Time } & \multicolumn{3}{|c|}{ Glucose concentration subject (mg/dl) } & \multirow[b]{2}{*}{$\overline{\mathrm{X}} \pm$ SEM } & \multicolumn{3}{|c|}{ Glucose enrichment (MPE) subject } & \multirow[b]{2}{*}{$\overline{\mathrm{X}} \pm$ SEM } \\
\hline & 1 & 2 & 3 & & 1 & 2 & 3 & \\
\hline \multicolumn{9}{|l|}{$\min$} \\
\hline \multicolumn{9}{|l|}{ Basal } \\
\hline-30 & 83 & 102 & 93 & $92.67 \pm 5.49$ & 2.20 & 2.50 & 2.33 & $2.34 \pm 0.087$ \\
\hline-20 & 84 & 100 & 95 & $93.0 \pm 4.72$ & 2.17 & 2.53 & 2.30 & $2.33 \pm 0.105$ \\
\hline-10 & 78 & 101 & 97 & $92.0 \pm 7.09$ & 2.23 & 2.52 & 2.28 & $2.34 \pm 0.090$ \\
\hline 0 & 79 & 103 & 95 & $92.3 \pm 7.06$ & 2.21 & 2.51 & 2.30 & $2.34 \pm 0.089$ \\
\hline \multicolumn{9}{|l|}{ Exercise } \\
\hline 10 & 84 & 105 & 94 & $94.3 \pm 6.06$ & 2.26 & 2.61 & 2.28 & $2.38 \pm 0.113$ \\
\hline 20 & 82 & 101 & 96 & $93.0 \pm 5.69$ & 2.21 & 2.58 & 2.31 & $2.37 \pm 0.111$ \\
\hline 30 & 79 & 100 & 93 & $90.67 \pm 6.17$ & 2.28 & 2.53 & 2.36 & $2.39 \pm 0.074$ \\
\hline 40 & 81 & 98 & 91 & $90.0 \pm 4.93$ & 2.25 & 2.59 & 2.29 & $2.38 \pm 0.107$ \\
\hline 50 & 80 & 99 & 89 & $89.3 \pm 5.49$ & 2.29 & 2.62 & 2.32 & $2.41 \pm 0.105$ \\
\hline 60 & 79 & 104 & 91 & $91.3 \pm 7.22$ & 2.28 & 2.57 & 2.38 & $2.41 \pm 0.085$ \\
\hline \multicolumn{9}{|c|}{ Recovery } \\
\hline 70 & 81 & 107 & 90 & $92.67 \pm 7.62$ & 2.32 & 2.63 & 2.44 & $2.46 \pm 0.09$ \\
\hline 80 & 83 & 105 & 91 & $93.0 \pm 6.43$ & 2.40 & 2.78 & 2.63 & $2.60 \pm 0.111$ \\
\hline 90 & 82 & 101 & 92 & $91.67 \pm 5.49$ & 2.51 & 2.81 & 2.84 & $2.72 \pm 0.105$ \\
\hline \multicolumn{5}{|c|}{ Enrichment of exogenous glucose } & 2.18 & 2.45 & 2.35 & $2.33 \pm 0.079$ \\
\hline
\end{tabular}

Subjects were infused with somatostatin $(0.1 \mu \mathrm{g} / \mathrm{kg} \cdot \mathrm{min})$, insulin $(\sim 0.2 \mathrm{mU} / \mathrm{kg} \cdot \min )$, and glucagon $(1.4 \mathrm{ng} / \mathrm{kg} \cdot \min )$ throughout rest, exercise, and recovery. Exogenous glucose was infused at $2 \mathrm{mg} / \mathrm{kg} \cdot \min$ throughout exercise and recovery. $\left[1-{ }^{13} \mathrm{C}\right] \mathrm{glucose}$ was infused at the rate of 0.05 $\mathrm{mg} / \mathrm{kg} \cdot \mathrm{min}$ throughout all three periods. 
insulin concentration. This possibility was prevented in our experiment because of the replacement of insulin. Thus, it seems that a low level of insulin contributes to the stimulatory effect of glucagon on glucose production in exercise.

Our study was not intended to assess factors contributing to exhaustion during exercise. The exercise intensity was well below a level that would be expected to cause fatigue. It was therefore surprising that the subjects in the high-insulin group either could not complete the exercise $(n=2)$ or could complete it only with great effort $(n=4)$. Inadequate oxygen delivery could not have been a factor contributing to exhaustion, because the average heart rate in the high-insulin group was only 111 beats per minute, far below the maximal heart rate (estimated to be around $\sim 190$ beats per minute). Cardiac output determination performed by $\mathrm{CO}_{2}$ rebreathing (22) in two subjects in each group confirmed that exhaustion occurred in the high-insulin group even though the average cardiac output was 11.3 liters/min, well below the estimated maximal level of 25 liters/min. Muscle glycogen depletion seems an unlikely cause of exhaustion in this study. If it is assumed that the concentration of muscle glycogen was $20 \mathrm{~g} / \mathrm{kg}$ wet muscle (23) and that there was $20 \mathrm{~kg}$ of working muscle (24), a total of $400 \mathrm{~g}$ of glycogen would have been available at the start of exercise. For subject E.N., a total of $2.64 \mathrm{~mol}$ of $\mathrm{CO}_{2}$ above the basal level were produced during exercise. Even if all of that $\mathrm{CO}_{2}$ was from the oxidation of glucose-6phosphate derived from muscle glycogen, only $79 \mathrm{~g}$ of glycogen would have been oxidized. Therefore, it seems likely that hypoglycemia was the cause of exhaustion in the subjects that had to stop. The role of hypoglycemia in causing exhaustion was verified in the three subjects who repeated the high-insulin protocol, since glucose infusion in the repeat test eliminated the feeling of exhaustion. All three completed the repeat test (with glucose infusion) with no problems.

In conclusion, the results of this experiment demonstrate the importance of subtle changes in insulin and glucagon in the maintenance of plasma glucose homeostasis in humans in light exercise, despite the difficulty in measuring such changes. There appears to be an increased peripheral sensitivity to the action of insulin, which leads to an increase in glucose uptake and hence oxidation. Consequently, a slight decrease in insulin is necessary so that the rate of glucose uptake does not exceed the ability of glucose production to keep pace. The appropriate stimulation of glucose production in exercise seems to result from a combination of increased glucagon activity, coupled with a decrease in insulin. If both of these hormonal responses to exercise are prevented pharmacologically, severe hypoglycemia develops and exhaustion results, despite only moderate cardiovascular stress.

\section{Acknowledgments}

The authors wish to thank Judy Chadwick for the typing and preparation of this manuscript.

This work was supported by National Institutes of Health grant AM34817-01 and Division of Research Resources GCRC grant RR-73.

\section{References}

1. Ahlborg, G., P. Felig, L. Hagenfeldt, R. Hendler, and J. Wahren. 1974. Substrate turnover during prolonged exercise in man. Splanchnic and leg metabolism of glucose, free fatty acids and amino acids. J. Clin. Invest. 53:1080-1090.

2. Felig, P., and J. Wahren. 1975. Fuel homeostasis during exercise. N. Engl. J. Med. 293:1078-1084.
3. Vranic, M., R. Kawamori, S. Pek, N. Kovacevic, and G. A. Wrenshall. 1976. The essentiality of insulin and the role of glucagon in regulating glucose utilization and production during strenuous exercise in dogs. J. Clin. Invest. 57:245-255.

4. Issekutz, B., Jr., and M. Vranic. 1980. Role of glucagon in regulation of glucose production in exercising dogs. Am. J. Physiol. 28:E13-E20.

5. Wasserman, D. H., H. L. A. Lichley, and M. Vranic. 1984. Interactions between glucagon and other counterregulatory hormones during normoglycemic and hypoglycemic exercise in dogs. J. Clin. Invest. 741: 1404-1413.

6. Zinman, B., E. B. Marliss, A. K. Hanna, H. L. Minuk, and M. Vranic. 1981. Exercise in diabetic man: glucose turnover and free insulin responses after glycemic normalization with intravenous insulin. Can. J. Physiol. Pharmacol. 60:1236-1240.

7. McGuire, E. A. H., J. H. Helderman, J. D. Tobin, R. Andres, and M. Berman. 1976. Effects of arterial versus venous sampling on analysis of glucose kinetics in man. J. Appl. Physiol. 41:565-573.

8. Wolfe, R. R. 1984. Tracers in Metabolic Research: Radioisotope and Stable Isotope/Mass Spectrometry Methods. Alan R. Liss, Inc., New York. 41-55.

9. Cowan, J. S., and G. Hetenyi, Jr. 1971. Glucoregulatory responses in normal and diabetic dogs recorded by a new tracer method. Metabolism. 20:360-372.

10. Wolfe, R. R., J. R. Allson, and J. F. Burke. 1979. Glucose metabolism in man: responses to intravenous glucose infusion. Metabolism. 28:210-220.

11. Albano, J. D. M., R. P. Ekins, G. Maritz, and R. C. Turner. 1972. A sensitive precise radioimmunoassay of serum insulin relying on charcoal separation of bound and free hormone moieties. Acta Endocrinol. 70:487-509.

12. Faloona, G. R., R. H. Unger, R. J. Chambers, S. R. Bloom, G. Duncan, R. H. Johnson, and W. R. Sulaiman. 1974. Methods of Hormone Radioimmunoassay. B. M. Jaffee, and H. R. Behrman, editors. Academic Press, Inc., New York. 317-330.

13. Hjemdahl, P., M. Daleskog, and T. Kahan. 1979. Determination of plasma catecholamines by high performance liquid chromatography with electrochemical detection: comparison with a radioenzymatic method. Life Sci. 25:131-138.

14. Steele, R. 1959. Influences of glucose loading and of injected insulin on hepatic glucose output. Ann. NY Acad. Sci. 82:420-430.

15. Wolfe, R. R., J. H. F. Shaw, E. R. Nadel, and M. H. Wolfe. 1984. Effect of substrate intake and physiological state on background ${ }^{13} \mathrm{CO}_{2}$ enrichment. J. Appl. Physiol. 56:230-234.

16. Chalmers, R. J., S. R. Bloom, G. Duncan, et al. 1979. The effect of somatostatin on metabolic and hormonal changes during and after exercise. Clin. Endocrinol. 10:451-458.

17. Cherrington, A. D., M. D. Caldwell, M. R. Dietz, J. R. Exton, and O. B. Crofford. 1977. The effect of somatostatin on glucose uptake and production by rat tissues in vitro. Diabetes. 26:740-748.

18. Blackard, W. G., and N. C. Nelson. 1970. Portal and peripheral vein immunoreactive insulin concentrations before and after glucose infusion. Diabetes. 19:302-306.

19. Koivisto, V., V. Soman, E. Nadel, W. V. Tamborlane, and P. Felig. 1980. Exercise and insulin: insulin binding, insulin mobilization and counterregulatory hormone secretion. Fed. Proc. 39:1481-1486.

20. Berger, M., S. Hagg, and N. B. Ruderman. 1975. Glucose metabolism in perfused skeletal muscle. Interaction of insulin and exercise on glucose uptake. Biochem. J. 146:231-238.

21. Richter, E. A., L. P. Garetto, M. N. Goodman, and N. B. Ruderman. 1982. Muscle glucose metabolism following exercise in the rat. Increased sensitivity to insulin. J. Clin. Invest. 69:785-793.

22. Farhi, L. E., M. S. Nesarajah, A. J. Olszowka, L. A. Metiddi, and A. K. Ellis. 1976. Cardiac output determination by simple one-step rebreathing technique. Respir. Physiol. 28:141-159.

23. Karlsson, J., and B. Saltin. 1971. Diet, muscle glycogen and endurance performance. J. Appl. Physiol. 31:203-206.

24. Mitchell, J. W., J. A. J. Stolwijk, and E. R. Nadel. 1972. Model simulation of blood flow and oxygen uptake during exercise. Biophys. J. 12:1452-1466. 